\title{
The Unimportance of Homework in College Education
}

\author{
Zhijia Pan ${ }^{a,{ }^{*}}$, Zhongren Feng ${ }^{b}$ and Haiqing Yuan ${ }^{c}$ \\ Wuchang Shouyi University, China \\ axiaofeixiafeifei@126.com, b443466604@qq.com, cyuanhq126@126.com
}

${ }^{*}$ Corresponding author

Keywords: Classroom work, Lecture, Homework, Performance.

\begin{abstract}
Two classes were lectured by the same lecturer with the same lecture. One class was chosen to give mathematical practices in class while the other was given the exact same practices during and after class. Compare the performance of students in class as well as the scores in the final exam to figure out which class has the better improvement in learning. In the end of the semester, anonymous questionnaires are handed out to students to see the real thoughts of them about homework and classroom work. Results show that students prefer to have less homework and homework in college actually is not helpful for their study and learning. Colleges, universities may find a way to decrease homework and increase practices during class in the hope of a better result and more favorable acceptance from students.
\end{abstract}

\section{Introduction}

Chinese students have been drowned in endless homework especially before college for homework has been proved to be one of the most efficient way to brush over and review the just-learned knowledge during school. The distinction between academic performance in college and middle school or elementary school presents a question whether homework is the best way to test any student's attitude and capacity of learning. Entering into college is like opening a free door to the hardworking Chinese students who have not much time of their own but being put into different kinds of classes and different kinds of homework both from school and their good willed parents. A lot of college students actually are trying to compensate their loss in the past by playing with their friends and having fun. College students even those who are in the first class universities are said to have difficulties to fulfill the commitment of doing homework on time by themselves. Lecturers in college bluntly point out that college students are getting lazy. But is that the righteous understanding of the young generation who are supposed to take the future social responsibilities after graduation?

The concept of college originated in western countries actually is a new form of education in China, which developed only in the last century and has been still trying to find its own way to be accommodated into this ancient culture. Discarding the old tradition of learning just literature in private schools from only one lecturer for years, China had the most enthusiasm to cope with the change of a new era of education. Homework is not a problem at all because it is all the same as former schooling. With the development in economy and globalization, college education that was and still is sophisticated in western world came into China in two interesting ways. One is to upgrade the education system by incorporating Chinese traditional education methods and western ones, the other is to copy everything from outside by blighting the old traditions. The former seems to struggle to find its standing ground while the latter, regardless of the obvious degradation of academic performance of students, go straight to the modern schooling.

The world full of entertainments from internet, TV, radio, smart phones and so on, takes away the focus of students from real schooling. Lecturers are giving homework to students to try to keep them stay focused on study. Discussion about whether it's an efficient way of education in college never stops, but more and more lecturers even professors say that homework is neither the best way to attract students' interest and focus nor to tell the academic difference between them. To find the statistical evidence of this conclusion, since literally no one in engineering fields has done any 
research like this, one experiment has been planned to be completed in Wuchang Shouyi University in the fifth semester of Grade 2014 in the major of Engineering Cost.

\section{Preparation}

\subsection{Analysis of feasibility}

Research of how to make real-time lecture more interesting and efficient for both lecturers and students have long been a hot topic in education field such as PPT teaching and blackboard teaching comparison, attention attraction and multimedia usage. They had been discussed and put into practice already by lecturers in college [1][2]. This experiment of putting homework and classroom work into consideration for better performance of students were only carried out by a couple of lecturers in statistics fields and none in engineering fields for the reason mentioned in the first part [3]. To make the experiment practical, some conditions should be considered before its start. First, class choice. How many classes should be chosen for the experiment and why. Second, how to process the experiment. And last, how to compare the results from the experiment to make the conclusion.

\subsection{Class choice}

Geotechnical Engineering is one of the basic subject' s students in Civil Engineering and related fields must learn and master in college. It involves soil, the matter, and foundation, which is built or built on or built in soil. Every engineering project ranging from houses to rocket launching facilities needs to be set up from its foundation [4]. Usually, more difficult the project is, more time and money would be put into its foundation part. It is said that expense of foundations of tall buildings cost almost one fourth of its whole budget. Thus learning Geotechnical Engineering well determines the quality potential of any engineering project, which makes the subject proper for the experiment.

Homework is an indispensable part of learning the subject because it needs students to memorize theory equations as well as particular terminology definitions and explanations in the field. To find the importance of homework, an experiment was planned before the beginning of the fifth semester. Two classes were chosen for its similarity in learning environment. Those two classes are both from the major of Engineering Cost so they have the same curriculum even under the same supervisor during campus time and the same lecturer to give out the lecture. The subject requires former knowledge of Physics and Engineering Mechanics, the average score of the two subjects in the two classes should have as little difference as possible. Taking all the requirements mentioned above, class 1 and class 3 of Engineering Cost were chosen for the experiment.

$$
\begin{gathered}
\mathrm{x}^{*}=\left(\mathrm{x}_{1}+\mathrm{x}_{2}+\cdots+\mathrm{x}_{\mathrm{n}}\right) / \mathrm{n} \\
\mathrm{w}=\left[\left(\mathrm{x}_{1} *-\mathrm{x}_{2} *\right) / \mathrm{x}_{2} *\right] / \mathrm{n}
\end{gathered}
$$

$\mathrm{x}_{1}, \mathrm{x}_{2} \cdots \mathrm{x}_{\mathrm{n}}$ is the score of each student in one class for one subject. $\mathrm{n}$ is the total number of students in that class. $\mathrm{x} *$ represents the average score of one class for one particular subject. $\mathrm{x}_{1} *$ here, for convenience, stands for the higher average score of one class for the subject while $\mathrm{x}_{2} *$ stands for the lower average score of the other class for the same subject. Class 1 of Engineering Cost has together 30 students and its average score of physics is 61.07. Class 3 of Engineering Cost has the same student number, 30, and its average score of physics is 61.33. The average score of Engineering Mechanics for class 1 and 3 are respectively 63.00 and 63.47. w is the so called deviation percentage which is usually used to see how far one thing distance the other. It is used to see the deviation of the two classes, the smaller it is, more similar they are. Deviation of Physics and Engineering Mechanics are calculated to be $0.43 \%$ and $0.75 \%$. Both are really small, so the two classes are quite proper for the experiment. To see the result expected, deviation percentage of the final exam between two classes is one important factor to be considered.

\subsection{Learning points}

The text book chosen is the Engineering Geology and Foundation written by Li hongjiang. It has 12 chapters together, but only 9 chapters were lectured out in the class according to the syllabus of the 
department of Unban Construction in Wuchang Shouyi University. Learning points of the 9 chapters were consciously organized into class and explained in the direction of entrance examination requirements for higher education. In the hope of making learning points digested well, classroom work are also needed. Homework of every week is aimed to make students train their habits of reviewing what they have learned during class and to keep a habit of learning.

Table 1. Chapters chosen for the lecture.

\begin{tabular}{cc}
\hline Chapter & Content \\
\hline 1 & Introduction of Engineering Geology \\
\hline 2 & Foundation Soil \\
\hline 3 & Stress of Self Weight and Settlement \\
\hline 4 & Shear Strength and Bearing Capacity \\
\hline 5 & Soil Pressure and Slope Stability \\
\hline 7 & Shallow Foundation \\
\hline 8 & Deep Foundation \\
\hline 9 & Foundation Ditch Work \\
\hline 12 & Special Foundation Soil \\
\hline
\end{tabular}

The above chapters cover the most important learning points in Geotechnical Engineering. Such as the formation process of soil in chapter 1, the nature and its structure in chapter 2, self-weight calculation in chapter 3, shear strength theory in judging whether the soil would break its present formation or not under certain pressure in chapter 4, soil pressure in two different situations in chapter 5 , shallow foundation design in chapter 7 , pile foundation design in chapter 8 , introduction to foundation ditch work in chapter 9 and refinements of special foundation soil in chapter 12 . All the learning points in the whole textbook were concluded from former experience in lecturing and analysis of the entrance examination for higher education. In that case, the experiment could be more practical and meaningful to both lecturers and students.

\section{Process and comparison}

\subsection{Classroom work and homework}

To make the process of the experiment clearer, the conclusion more useful, class 1 was arranged to have homework while class 3 has none. Two classes need to have the same materials for learning, equivalent arrangement during class so that the only factor affects the result of the experiment would be constrained to only homework. Experience from past semesters gave a clue that if anyone wants to learn Geotechnical Engineering well, practices of certain parts and memorization of important learning points is the key. If mathematical practice were put into homework and nowhere else, the result could be very distinct but not responsible to students who had not sufficient practice of learning. Thus classroom work was consciously added into the experiment to make students who were not assigned homework also had the chance to learn well. Homework then should be cut less. All the important learning points were subdivided into 14 weeks, that is 52 class periods, and 7 times of homework were planned to be given to class 1 because of the difficulty of the completion of homework. Classwork covers all the learning points from chapter 1 to 12 . One lecturer was pointed to roll out the lecture in the same way and also needed to notice the performance of students in class.

\subsection{Judgement}

Performance of students in class has two sides to be observed. One is how long they can focus on catching up with the lecturer. PPT teaching is chosen because of its big screen, formalized characters and clear pictures or videos. Content even the order of the lectures should be the same in class 1 and class 3. If one class lagged in learning, it is necessary to put less time in some less important parts to even the whole process. Learning points and classroom work should also be checked immediately after it is done to make most students understood and focused in lectures. But an interesting thing comes up that students of class 1 seemed to have more energy than class 3 in class. 
Since all the factors were kept similar to each other except homework arrangement, it becomes the only factor that influences the result. The score of the final exam has come. The average score of the final exam for class 1 is 62.7 . Two students pass 80 , the ratio is $6.67 \%$. The average score of the final exam for class 3 is 64.33 . Six students pass 80 , the ratio is $20 \%$. The deviation of the exam is $2.6 \%$, which shows the degree of improvement increased. Homework does not level up the performance, classroom work does.

At the same time, one questionnaire was handed out when all the lectures were over to see how students feel about homework and classroom work. 60 questionnaires were given out and 57 were collected back, 2 of which were invalid. 36 students support to lessen homework and increase classroom work that is $65.5 \%$ of the whole group. And only 19 students support to stay in the tradition and keep the old way.

\section{Summary}

More students are inclined to lessen homework and increase classroom work. The world changes with more distractions were around college and younger generations. To make most use of class time is somewhat more suitable for the new trend of higher education. And the practice of lessening homework creates improvements of students' performance in exams. One thing attracts the attention is that in-class performance does not say the same thing of plan. Students in class 1 with homework put more energy into class than class 3 . And this may leave more to think about for future researchers in the education field.

\section{References}

[1] Z.J. Pan, H.Q. Yuan and S.Z. Zhu, Necessity of getting involved in Special English learning, Advances in Social Science, Education and Humanity Research, vol.40, pp. 335-338, 2016.

[2] Z.J. Pan, H.Q. Yuan and S.Z. Zhu, The importance of reasonably allocating time in Architectural Drafting and CAD lectures, 2nd International Conference on Humanities Science and Society Development, vol.155, pp. 30-33, 2017.

[3] H. Zhang, Research of multiple dimensional homework construction, Higher Education Exploration, vol.2, pp. 80-82, 2015.

[4] B.T. Duan, Civil Engineering, Special Engish for Civil Engineering, vol. 2, pp. 1-3, 2004. 